\title{
Asymmetric and node-specific nodal expression patterns are controlled by two distinct cis-acting regulatory elements
}

\author{
Dominic P. Norris and Elizabeth J. Robertson ${ }^{1}$ \\ Department of Molecular and Cellular Biology, Harvard University, The Biological Laboratories, \\ Cambridge, Massachusetts 02138 USA
}

\begin{abstract}
The TGFß-related molecule Nodal is required for establishment of the anterior-posterior (A-P) and left-right (L-R) body axes of the vertebrate embryo. In mouse, several discrete sites of nodal activity closely correlate with its highly dynamic expression domains. nodal function in the posterior epiblast promotes primitive streak formation, whereas transient nodal expression in the extraembryonic visceral endoderm is essential for patterning the rostral central nervous system. Asymmetric nodal expression in the developing node and at later stages in left lateral plate mesoderm has been implicated as a key regulator of L-R axis determination. We have analyzed the cis-regulatory elements controlling nodal expression domains during early development. We show that the regulatory sequences conferring node-specific expression are contained in an upstream region of the locus, whereas early expression in the endoderm and epiblast and asymmetric expression at later stages on the left side of the body axis are controlled by a 600-bp intronic enhancer. Targeted deletion of a 100-bp subregion of this intronic enhancer eliminates nodal expression in the early epiblast and visceral endoderm and disrupts asymmetric expression in the node and lateral plate mesoderm. Thus, developmentally regulated nodal expression at distinct tissue sites during A-P and L-R axis formation is potentially controlled by common transcriptional activators.
\end{abstract}

[Key Words: Mouse development; axis formation; TGF $\beta$ signaling; left-right asymmetry; nodal]

Received April 6, 1999; revised version accepted May 6, 1999.

The activities of secreted growth factors belonging to the TGF $\beta$ superfamily are critical for establishing the body axes of the vertebrate embryo. In particular, nodal homologs have been shown to contribute at distinct stages both during the initial specification and subsequent elaboration of the anterior-posterior (A-P) axis. In mouse, nodal signals are required for the formation of the primitive streak and initiation of gastrulation (Zhou et al. 1993; Conlon et al. 1994). Similarly, Xnr-1 and $X n r-2$ function in Xenopus to promote mesoderm induction and patterning (Jones et al. 1995; Smith et al. 1995). Recent studies in both mouse (Varlet et al. 1997) and zebrafish (Feldman et al. 1998; Rebagliati et al. 1998a; Sampath et al. 1998) demonstrate nodal activities are necessary for development of the anterior central nervous system (CNS). nodal genes also act in a conserved molecular pathway to determine the left-right (L-R) axis, the process by which distinct and invariant handedness is conferred upon the embryonic body plan. Thus in all vertebrates examined, expression of a nodal family member exclusively in left lateral plate mesoderm (LPM) precedes the development of overt differences between the left and right sides of the embryo (Levin et al. 1995;

${ }^{1}$ Corresponding author.

E-MAIL ejrobert@fas.harvard.edu; FAX (617) 496-6770.
Collignon et al. 1996; Lowe et al. 1996; Rebagliati et al. 1998b). In chick and mouse only a single nodal gene has been identified to date, whereas multiple nodal-related genes have been cloned from zebrafish (Rebagliati et al. 1998b) and Xenopus (Jones et al. 1995; Smith et al. 1995; Lustig et al. 1996; Joseph and Melton 1997). Biochemical and genetic studies show these related ligands have both unique and partially overlapping functions. Thus, Xnr-1 and $X n r-2$ are both potent inducers of dorsal mesoderm (Jones et al. 1995), but ectopic expression of Xnr-1 selectively leads to reversal of body situs (Sampath et al. 1997). By contrast, Xnr-3 acts as a neural inducer (Hansen et al. 1997). In zebrafish, the cyclops and squint mutants represent loss-of-function alleles at two independent nodal loci (Feldman et al. 1998; Rebagliati et al. 1998a; Sampath et al. 1998). Interestingly, squint has been shown to act as a recessive enhancer of the cyclops phenotype, suggesting these ligands have partially redundant functions during anterior patterning (Feldman et al. 1998).

In the postimplantation mouse embryo, sites of nodal functional activity closely correlate with highly dynamic expression domains. Thus, our previous studies have shown that nodal expression in the posterior epiblast is required for primitive streak formation, whereas transient nodal expression in the extraembryonic vis- 
ceral endoderm is essential for patterning the most anterior regions of the CNS (Varlet et al. 1997). These experiments suggest that nodal plays a key role during establishment of the anterior organizing center or AVE in the pregastrulation stage embryo (for review, see Beddington and Robertson 1998). Based on its node-specific expression pattern at later stages (Zhou et al. 1993; Conlon et al. 1994; Collignon et al. 1996), nodal has also been implicated in the formation and/or function of the mouse node, the organizing center responsible for patterning the midline and posterior regions of the embryo (Beddington and Robertson 1999). By early somite stages, asymmetric nodal expression domains are detected both in the node as well as in the left LPM /Collignon et al. 1996; Lowe et al. 1996). A second TGF $\beta$ family member lefty-2 is also asymmetrically expressed in the left LPM (Meno et al. 1997), suggesting that nodal and lefty-2 may share transcriptional regulatory elements. Consistent with this idea, asymmetric expression of both genes is similarly perturbed in inversion of embryonic turning $(i n v)$ and situs inversus viscerum (iv) mutant embryos that develop abnormal body situs (Collignon et al. 1996; Lowe et al. 1996; Meno et al. 1996, 1997). Functional studies in chick have also demonstrated that nodal misexpression affects heart looping and polarity of visceral organs (for review, see Harvey 1998). Recent studies demonstrate that pitx2, a homeodomain transcription factor of the bicoid class, is an important downstream target of the nodal pathway (for review, see Harvey 1998). Thus, ectopic nodal expression in chick embryos induces pitx2 (Logan et al. 1998; Piedra et al. 1998; Ryan et al. 1998), and right-sided pitx2 expression alone is sufficient to interfere with establishment of situs (Logan et al. 1998; Ryan et al. 1998). In chick, nodal may also act to repress left-sided expression of molecules such as the transcription factor Snr-1 (Issac et al. 1997). Collectively these data suggest that asymmetric nodal and lefty-2 expression domains play a key role during specification of the L-R body axis (Beddington and Robertson 1999).

As for other TGF $\beta$ family members, Nodal is thought to act by binding to cell surface serine-threonine receptor kinases, classified as type I or type II according to structural and functional criteria (for review, see Massagué 1996). The diverse ligand binding and signaling properties of TGF $\beta$ receptor kinases have been analyzed extensively (for review, see Massagué 1998). The formation of a heteromeric complex between type I and type II receptor kinases results in the activation of downstream intracellular targets (Wrana et al. 1994). Functionally distinct type I receptors selectively phosphorylate different Smad effector proteins that function as transcriptional activators (for review, see Massagué 1998; Whitman 1998). In Xenopus overexpression of Xnr-1 and Xnr-2 leads to formation of dorsal mesoderm (Jones et al. 1995), an effect that can be blocked by coinjection of a dominant-negative form of the Xenopus type 1 activin receptor ALK4 (Piccolo et al. 1999). Thus, these nodal homologs may normally activate the TGFß/activinSmad2/Smad3 pathway to influence cell fate. In mouse, loss-of-function mutations in ALK3 (Mishina et al. 1995) and ALK4 (Gu et al. 1998), corresponding to BMP and activin type I receptors, respectively, arrest embryonic development prior to gastrulation, suggesting these receptors may be involved in transducing nodal signals at early stages. Consistent with this idea, both ALK4 and Smad2, an effector of the TGF $\beta /$ activin pathway, are essential for the contribution made by the extraembryonic lineages in establishing anterior pattern in the early embryo (Gu et al. 1998; Waldrip et al. 1998), as expected for molecules acting in the nodal pathway. However, the various components of Nodal-specific receptor complexes and cell-type specific downstream targets responsible for nodal signaling at diverse tissue sites have yet to be elucidated.

We now have a rudimentary understanding of the tissue interactions and some of the molecular components essential for establishment of the key organizing centers of the early mouse embryo, namely the AVE and the node (for review, see Beddington and Robertson 1998, 1999|. For example, HNF3 $\beta$, a member of the Fork head family of transcription factors, is necessary for the formation of the node (Ang and Rossant 1994; Weinstein et al. 1994). A complex pattern of HNF3 $\beta$ expression is generated via the combined activities of multiple enhancer and repressor elements (Sasaki and Hogan 1996). Considerable data suggest that HNF3 $\beta$ acts to control the expression domains of important downstream signaling molecules, such as Sonic hedgehog (Shh), that pattern the later-stage embryo (Epstein et al. 1999). Transcription factors acting at restricted sites may similarly be responsible for establishment of nodal and lefty asymmetries. Given the central role played by nodal during anterior patterning, formation of the primitive streak, and L-R axis determination, it is of considerable interest to understand nodal transcriptional control mechanisms at these different stages of embryonic development.

Here we used a conventional transgenic approach to map cis-acting regulatory elements controlling nodal expression domains. The sequences that confer node-specific expression are contained in a $2.7-\mathrm{kb}$ upstream flanking region. By contrast, early expression in the visceral endoderm and epiblast and asymmetric expression at later stages on the left side of the body axis are controlled by a 600-bp intronic enhancer. Moreover, expression of transgenes carrying this asymmetric enhancer element is perturbed in both the inv and iv mutant backgrounds. Targeted deletion of a 100-bp region contained within the asymmetric enhancer of the endogenous nodal locus selectively eliminates nodal expression in the early epiblast and visceral endoderm lineages, and also renders the locus insensitive to the signals governing asymmetric expression in the node and LPM. The present experiments thus identify two distinct transcriptional enhancer regions governing highly dynamic patterns of nodal gene expression.

\section{Results}

Identification of the minimal promoter

The nodal locus is comprised of three coding exons span- 
ning $\sim 8 \mathrm{~kb}$ (Zhou et al. 1993; Fig. 1a). The transcriptional start site has not been previously mapped, and the first $327 \mathrm{bp}$ of the published cDNA sequence in exon 1 originate from genomic sequence $5^{\prime}$ to the presumed ATG translational start site. This $327-\mathrm{bp}$ region has all the hallmarks of a classical Pol II promoter and transient transfection assays established that the 5 ' region has promoter activity (D.P. Norris and E.J. Robertson, unpubl.). Thus, the transcription start site is $12 \mathrm{bp}$ upstream of the ATG. RNase protection assays have confirmed that nodal transcripts contain an unusually short 5' UTR (D. Constam and E.J. Robertson, unpubl.). Northern blots similarly show a single 1.8-2.0-kb nodal transcript lacking an appreciable 5' UTR (Conlon et al. 1994). DNase I hypersensitivity assays comparing chromatin prepared from embryonic stem (ES) cells, known to express nodal, with that from liver cells as a negative control identified two strong hypersensitive sites (HSs) specific to the expressed allele (denoted by arrows in Fig. 1a), the first mapping within the minimal promoter region and the second located $\sim 1 \mathrm{~kb}$ downstream of the first exon.

Two distinct enhancer regions control nodal expression at early somite stages

To identify enhancers responsible for nodal transcriptional regulation, we constructed transgenes containing nodal genomic subregions, a LacZ reporter cassette, and either the endogenous nodal or the hsp68 minimal promoter (Sasaki and Hogan 1996). We initially tested four nonoverlapping fragments encompassing $25 \mathrm{~kb}$ of genomic sequence (Fig. 1b). Constructs C1, C2, and C4 included the hsp68 minimal promoter whereas the $\mathrm{C} 3$ con- struct used the endogenous nodal minimal promoter. Initial screening was by transient analysis of embryos recovered at $\sim 8.5$ days of development, a stage at which nodal expression in both the node and the left LPM is readily detected (Collignon et al. 1996; Lowe et al. 1996; Fig. 2e). Age-matched embryos carrying the nodal.lacZ reporter allele were analyzed in parallel. The C1- and C3-containing transgenes resulted in variable ectopic lac $Z$ expression patterns indicating that these are position dependent and are usually repressed in the context of the endogenous locus (data not shown). We found a reproducible pattern of node specific $\beta$-gal expression in embryos carrying the $\mathrm{C} 4$ transgene $(-5$ to $-12 \mathrm{~kb}$; Fig. $1 \mathrm{~b}$ ). Expression was strictly confined to the periphery of the notochordal plate in a manner faithful to the endogenous pattern of nodal expression (Fig. 2). Moreover, in agreement with the pattern seen using the nodal.lac $Z$ allele, staining is also observed within the posterior notochord. After prolonged staining both the stable C4 line and the $\mathrm{F}_{\mathrm{O}}$ transgenic embryos show punctate expression in a minor population of cells surrounding the node.

In striking contrast, the $\mathrm{C} 2$ transgene $(+0.5$ to $+8 \mathrm{~kb})$ gave asymmetric $\beta$-gal expression confined to the left LPM. This expression domain extends along the entire length of the left LPM from the base of the allantois posteriorly to the level of the heart anteriorly (Fig. 3e). Expression is conspicuously absent from both the node and notochord. Analysis of tissue sections confirmed that lac $Z$ expression is confined to the mesoderm of the splanchnopleure and somatopleure. We also consistently observe LacZ staining in floor-plate cells of the neural tube. This cell population normally lacks nodal expression as assessed by whole-mount mRNA in situ or via

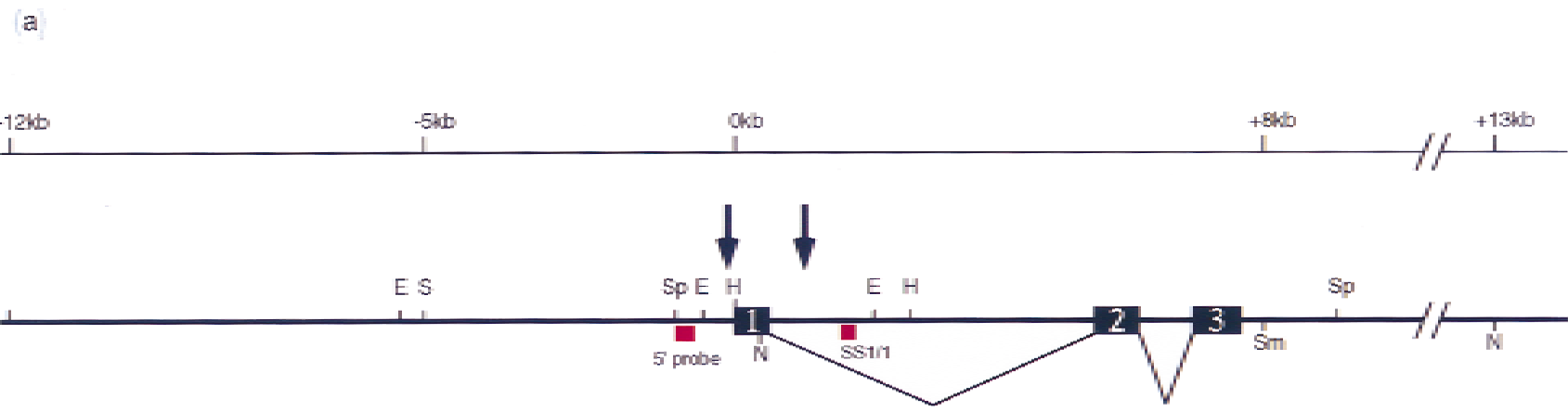

b

C4

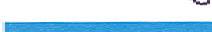

$\mathrm{C} 2$

\section{C3}
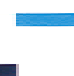

C1

Figure 1. The nodal locus contains two physically distinct cis-acting regulatory elements. (a) Genomic organization and restriction sites used to produce the reporter constructs; the extreme $5^{\prime}$ end corresponds to the $5^{\prime}$ extent of the $\lambda$ clone. Exons are shown as solid boxes. The positions of two DNase I hypersensitive sites specific to the expressed locus are signified by vertical arrows. Probes used for the hypersensitivity analysis are indicated in red. (E) EcoRI; (H) HindIII; (N) NotI; (S) SalI; (Sm) SmaI; (Sp) SpeI. (b) Genomic subregions used for production of reporter constructs. The fragments shown in blue gave LacZ staining patterns corresponding to nodal expression domains whereas those in black did not. 
a
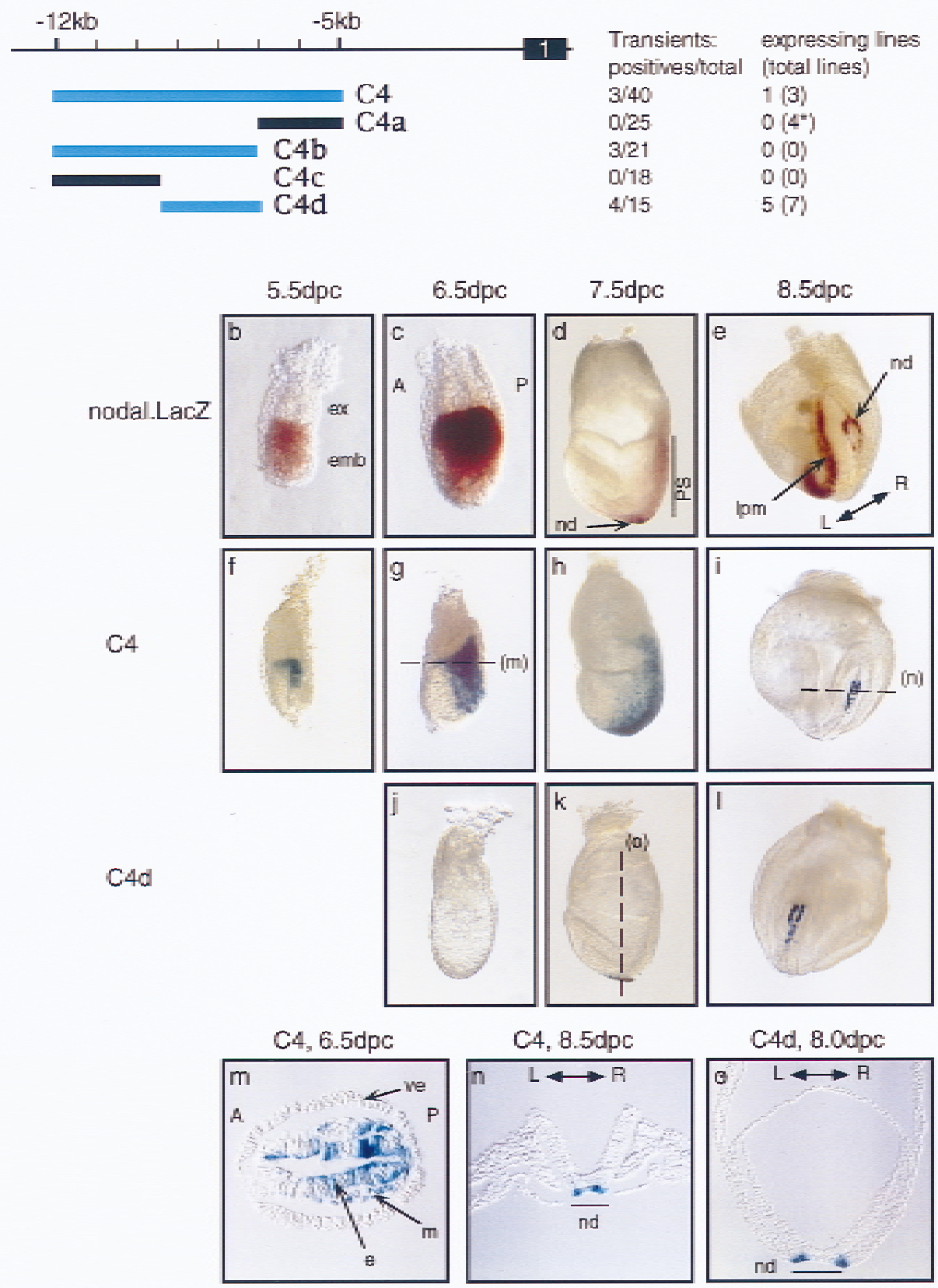

Figure 2. Fine mapping of the upstream region controlling node-specific expression. $(a)$ Genomic fragments analyzed in the delineation of the node specific element. Constructs giving expression within the node at $8.5 \mathrm{dpc}$ are shown in blue; nonexpressing ones are in black. The total number of positive embryos isolated is indicated over the total number of embryos analyzed in the transient analysis. The number of stable transgenic lines expressing within the node is indicated, together with the total number of transgene positive lines identified (in parentheses). (*) Three out of four C4a integrations expressed lacZ, but the staining patterns did not correspond to nodal expression domains, nor were results consistent between lines. $(b-e)$ Control nodal.1acZ/+ embryos were stained using Salmon-gal as the substrate. For 6.5- and 7.5-dpc embryos anterior $(\mathrm{A})$ is at left and posterior $(\mathrm{P})$ at right. For 8.5-dpc embryos the left $(\mathrm{L})$ and right $(\mathrm{R})$ sides of the axis are indicated. Expression patterns in embryos carrying a stable integration of the $\mathrm{C} 4$ transgene $(f-i)$ or a stable integration of the $\mathrm{C} 4 \mathrm{~d}$ transgene $(j-1)$ are shown. In $\mathrm{C} 4 \mathrm{~d}$ embryos, expression is not visible prior to node formation. $(m)$ Transverse section of 6.5-dpc C4 embryo. Expression is detected within the epiblast (e) and mesoderm (m) but not the visceral endoderm (ve). $(n)$ Frontal section through an 8.5-dpc C4 transgenic embryo. Expression is detectable within the periphery of the ventral layer of the node. Notably, transgene expression in the node lacks the marked asymmetry seen for the endogenous nodal locus. (o) Section through an 8.0-dpc C4d transgenic embryo. LacZ protein is localized symmetrically in the lateral edges of notochordal plate. (ex) Extra-embryonic region; (em) embryonic region; (nd) node; (ps) primitive streak; (lpm) lateral plate mesoderm. 
a
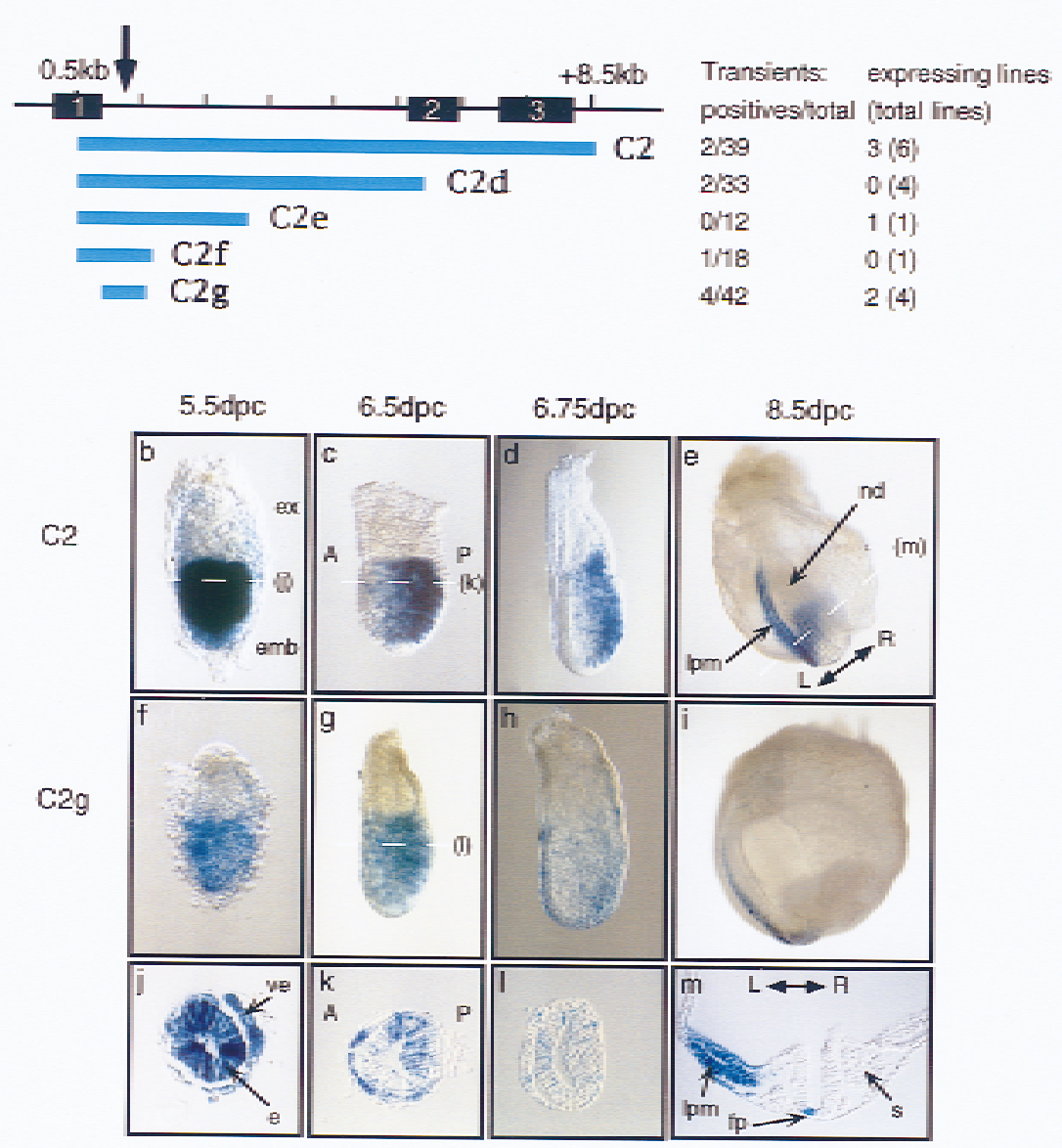

Figure 3. Fine mapping of the intronic enhancer responsible for asymmetric nodal expression. (a) Genomic fragments analyzed in the characterization of a minimal asymmetric enhancer. Positive embryos showed lacZ expression in the left LPM at 8.5 dpc. Expression patterns in embryos carrying a stable integration of the $\mathrm{C} 2$ transgene $(b-e)$ or a stable integration of the $\mathrm{C} 2 \mathrm{~g}$ transgene $(f-i)$ are shown. $(j, k)$ Transverse sections of $\mathrm{C} 2$ transgenic embryos at day 5.5 and $6.5 \mathrm{dpc}$, respectively, showing expression within the epiblast and visceral endoderm. (1) Transverse section of C2g embryo at $6.5 \mathrm{dpc}$ showing expression in the epiblast and visceral endoderm. $(m)$ Frontal section through an 8.5dpc C2 transgenic embryo. lacZ expression is detectable in the splanchnopleure and somatopleure of the lateral plate mesoderm, as well as in the left side of the floorplate (fp), but is absent from the somites (s). Orientation of embryos and labeling is as in Fig. 2.

analysis of the more sensitive nodal.lac $Z$ allele. As shown in Figure $3 \mathrm{~m}$, floor-plate expression is distinctly asymmetric, with $\beta$-gal activity confined to cells on the left side of the midline (see below). Moreover three founder lines carrying $\mathrm{C} 2$ gave similar patterns of $\beta$-gal expression. Thus, at 8.5 days of development the $\mathrm{C} 2$ and C4 transgenic constructs gave nonoverlapping expression patterns strongly suggesting that nodal expression is controlled by two distinct enhancer regions.

\section{A 2.7- $\mathrm{kb}$ upstream region contains the node enhancer}

The onset of nodal expression occurs at 5.0 days post coitum (dpc) in the visceral endoderm and throughout the epiblast (Varlet et al. 1997). nodal transcripts are initially detected throughout the visceral endoderm overlying the epiblast, but this expression is rapidly lost coincident with the initiation of gastrulation (Varlet et al. 1997). nodal expression is gradually down-regulated in the distal tip of the epiblast and becomes confined to cells within the prospective posterior proximal quadrant precisely marking the site of primitive streak formation (Collignon et al. 1996; Varlet et al. 1997; Fig. 2b,c). Shortly after the onset of gastrulation and elongation of the primitive streak, nodal expression becomes restricted to cells of the developing node (Collignon et al. 1996). To further describe cis-acting elements control- ling these complex expression domains we analyzed stable lines containing $\mathrm{C} 2$ and $\mathrm{C} 4$ transgenes. Embryos carrying a stable integration of the $\mathrm{C} 4$ transgene show very low levels of lac $Z$ expression detectable throughout the epiblast at $5.0 \mathrm{dpc}$ (data not shown). Approximately $12 \mathrm{hr}$ later, lacZ expression is confined to the proximal regions of the epiblast and subsequently becomes localized to the posterior side (Fig. 2f,g). In contrast there was no detectable expression in visceral endoderm cells (Fig. $2 \mathrm{~m}$, data not shown). Sectioning of early gastrulation stage embryos shows LacZ staining restricted to nascent mesoderm (Fig. $2 \mathrm{~m}$ ), as previously described for endogenous nodal transcripts (Varlet et al. 1997). At 7.5 dpc, expression was observed along the length of the primitive streak and in a patch of cells at the distal tip of the fully extended streak (Fig. 2h). As mentioned above, the C4 genomic subregion drives expression within the periphery of the node (Fig. 2i) specifically within the ventral layer of the notochordal plate (Fig. 2n).

To further dissect cis-acting regulatory elements, the 7.0-kb C4 genomic region was subdivided (Fig. 2a). The shorter $2.0-\mathrm{kb} \mathrm{C} 4 \mathrm{a}$ transgene failed to give detectable expression in $\mathrm{F}_{0}$ embryos recovered at $8.5 \mathrm{dpc}$, and four independent founder lines similarly gave negative results at all embryonic stages examined. In contrast, $\mathrm{F}_{0}$ embryos carrying the $\mathrm{C} 4 \mathrm{~b}$ transgene clearly showed lac $Z$ expression confined to the node (data not shown). This 
4.6-kb region was then further subdivided. At $8.5 \mathrm{dpc}$, the 2.0-kb C4c transgene failed to give expression in the node. The possible activity of the $\mathrm{C} 4 \mathrm{~b}$ and $\mathrm{C} 4 \mathrm{c}$ constructs at earlier stages of embryogenesis has not yet been analyzed. Five transgenic lines carrying stable integrations of C4d were generated, and four of these were found to express lacZ specifically within the node (Fig. 21). Thus, the node enhancer maps to the $2.7-\mathrm{kb} C 4 \mathrm{~d}$ fragment $(-7.5 \mathrm{~kb}$ to $-10.2 \mathrm{~kb})$. However, in marked contrast to the $\mathrm{C} 4$ construct, we fail to detect early lac $Z$ expression conferred by the $\mathrm{C} 4 \mathrm{~d}$ transgene prior to node formation (Fig. 2j,k). Thus, further work is needed to identify C4 enhancer(s) that contribute to nodal transcription in the epiblast.

At the three- to four-somite stage normal embryos show asymmetric nodal expression within the node, reflecting approximately twofold higher numbers of nodalpositive cells on the left side (Collignon et al. 1996). In contrast, embryos carrying either the C4 or C4d transgenes show equivalent node-specific staining on the left and right sides (Fig. 2n,o), implying that the asymmetric node element(s) maps outside the $7.0-\mathrm{kb}$ C4 region.

\section{The minimal asymmetric enhancer overlaps} with the HS site in intron 1

As shown above, the $\mathrm{C} 2$ transgene is sufficient to direct lac $Z$ expression exclusively on the left side of the body axis (Fig. 3e). To examine enhancer activities at earlier stages of development, we analyzed three independent transgenic lines. LacZ staining was consistently observed at $5.5 \mathrm{dpc}$ at high levels throughout the epiblast (Fig. 3b) and in the overlying visceral endoderm (Fig. 3j). Shortly before the initiation of gastrulation at $6.5 \mathrm{dpc}$, highest levels of expression are seen in the most proximal posterior regions of the epiblast (Fig. 3c). Transverse sections confirm $\beta$-gal staining is restricted to visceral endoderm and posterior epiblast cells (Fig. 3k). At 6.75 $\mathrm{dpc}, \mathrm{C} 2$ expression is initially confined to the posterior epiblast (Fig. 3d) and by 7.5 dpc largely disappears (data not shown). From the three-somite stage on asymmetric expression is observed within left LPM (Fig. 3e). Intriguingly, $\beta$-gal expression is also detectable in a small number of cells exclusively on the left side of the floor plate (Fig. $3 \mathrm{~m}$ ). As mentioned above, neither nodal mRNA nor nodal.1acZ activity is normally present in this cell population (Collignon et al. 1996; Lowe et al. 1996). However this expression pattern closely resembles that reported for the lefty-1 and lefty-2 genes (Meno et al. 1996, 1997). It is possible that the $\mathrm{C} 2$ genomic subregion lacks a repressor element that normally silences nodal expression at this site. Alternatively, the increased sensitivity afforded by high-copy transgenes (all three lines carry 5-8 copies of the transgene) potentially reveals a minor nodal expression domain.

The 8-kb C2 genomic subregion extends across the two downstream exons including a DNaseI HS within the first intron (Fig. 3a). To further delineate the asymmetric enhancer, we analyzed a nested series of transgenes. As shown in Figure 3, these fragments include and extend downstream of the HS. Results obtained in both transient transgenic embryos and founder lines map the left LPM enhancer to a $1.0-\mathrm{kb}$ subregion defined by the C2f transgene (Fig. 3a). The 596-bp fragment (C2g) containing the DNase I HS in intron 1 was subsequently amplified by PCR and analyzed by $\mathrm{F}_{\mathrm{O}}$ transgenesis. The C2g subregion gave expression within the left LPM at 8.5 dpc. Two stable lines carrying the $\mathrm{C} 2 \mathrm{~g}$ transgene show expression throughout the epiblast at $5.5 \mathrm{dpc}$ (Fig. 3f), and this domain gradually resolves to the posterior side over the next day of development (Fig. 3g). Transverse sections through the embryonic region show expression within the visceral endoderm (Fig. 31). Following extension of the streak to its distal limit, expression is greatly reduced but remains detectable on the posterior side of the epiblast (Fig. 3h). From the three-somite stage onwards, the $\mathrm{C} 2 \mathrm{~g}$ transgene faithfully recapitulates the asymmetric expression of the endogenous gene in the lateral plate (Fig. 3i). lacZ expression is detected synchronously along the full length of the left LPM and is down-regulated shortly after the initiation of embryonic turning (data not shown). Interestingly, the C2g transgene is not expressed in the midline of the floor plate, possibly because of the loss of a C2 transgene floor plate enhancer. Overall, these results demonstrate that the 596-bp minimal enhancer region spanning the intron 1 HS site includes cis-acting elements necessary for expression within the primitive endoderm, epiblast, and LPM.

\section{Asymmetric enhancer activity is perturbed in iv} and inv mutant embryos

The mutations iv and inv disrupt establishment of the L-R axis during early mouse development. iv, a recessive mutation resulting from an amino acid substitution in the L-R dynein (Lrd) protein (Supp et al. 1998), causes randomization of body situs (Hummel and Chapman 1959). The inv mutation in contrast causes a reversal of situs (Yokoyama et al. 1993). The transgene insertion at the inv locus largely deletes the coding region of a novel ankyrin repeat-containing protein (Mochizuki et al. 1998; Morgan et al. 1998). Both of these mutations perturb the normally asymmetric nodal and lefty expression patterns. In iv/iv embryos, nodal and lefty-2 expression domains are absent, bilateral, or random (Lowe et al. 1996; Meno et al. 1997), whereas nodal and lefty expression are for the most part reversed in inv/inv embryos (Collignon et al. 1996; Lowe et al. 1996; Meno et al. 1996).

To test whether the asymmetric enhancer element responds appropriately to regulatory cues, independent C2 transgenic lines were crossed into these mutant backgrounds. As shown in Figure 4, in the context of the inv mutation the majority of $\mathrm{C} 2$ transgenic embryos showed bilateral lacZ expression (Table 1). For the most part, roughly equivalent staining was observed on both sides of the axis, but occasionally embryos showed enhanced expression on the right (Fig. 4a,e). Thus, C2 transgene expression differs significantly from that observed for en- 
dogenous nodal transcripts found only on the right side of the axis in inv/inv embryos (Collignon et al. 1996; Lowe et al. 1996). On the other hand, C2 transgene expression more closely resembles that previously documented for endogenous nodal in the iv/iv background (Lowe et al. 1996). Thus, we observed unilateral expression on the left or right side, or bilateral expression (Fig. $4 \mathrm{f}, \mathrm{g})$, although, as for the inv mutants, an unexpectedly high proportion of embryos displayed bilateral expression (Table 1). Moreover, asymmetric expression in the floor plate mirrored that seen in the lateral plate (Fig. $4 \mathrm{~g}, \mathrm{~h})$. In striking contrast, as shown above, the C2 transgene was exclusively expressed on the left side in wildtype embryos.

\section{Targeted deletion of the asymmetric enhancer}

The 596-bp C2g genomic fragment (Fig. 5) contains several putative transcription factor binding sites, including those for GATA, HoxD8-10, Myf-3, MyoD, Sp1, and NF$\kappa B$. Except for the GATA family, none of these transcription factors is thought to be essential for early postimplantation mouse development. A retinoic acid response element (RARE) is present at position 360. This minimal asymmetric enhancer lacks consensus binding sites for the Gli proteins, effectors of the hedgehog signaling pathway. A novel 10-bp motif (CAATCCACAT) appears twice within a 100-bp region. Database searches (Heinemeyer et al. 1998) reveal no homology with any previ-
Table 1. Expression of the nodal asymmetric enhancer in iv/iv and inv/inv mutant embryos

\begin{tabular}{|c|c|c|c|}
\hline & $\begin{array}{c}C 2 /+, \text { inv } /+ \\
\times \\
+/+, i n v /+\end{array}$ & $\begin{array}{c}C 2 /+, \text { inv } /+ \\
\times \\
C 2 /+, \text { inv } /+\end{array}$ & $\begin{array}{c}C 2 /+, i v /+ \\
\times \\
+/+, i v /+\end{array}$ \\
\hline Total & 24 & 34 & 33 \\
\hline No expression & $10(12)$ & $11(8.5)$ & $17(17.5)$ \\
\hline Left & $11(9)$ & $17(19)$ & $8(13.5)$ \\
\hline Right & $0(3)$ & $1(6.5)$ & $2(1)$ \\
\hline Bilateral & $3(0)$ & $5(0)$ & $6(1)$ \\
\hline
\end{tabular}

Crosses between mice doubly heterozygous for the $C 2$ transgene and either iv or inv, result in a greater frequency of embryos expressing LacZ bilaterally than expected from previous published results. The number of embryos showing expression in either the left lateral plate (left), the right lateral plate (right), in both lateral plates (bilateral), or not at all (no expression) is indicated. The numbers shown in parentheses represent the expected number of embryos in each class (Collignon et al. 1996; Lowe et al. 1996). The total number of embryos collected for each cross is indicated at the top of each column.

ously characterized transcription factor binding sites but, interestingly, the minimal 380-bp asymmetric enhancer region recently identified for the lefty-2 locus (Saijoh et al. 1999) also contains two copies of this 10-bp sequence.

To further test the minimal 596-bp enhancer for its activity in conferring asymmetric expression, we designed targeting vectors to eliminate these sequences
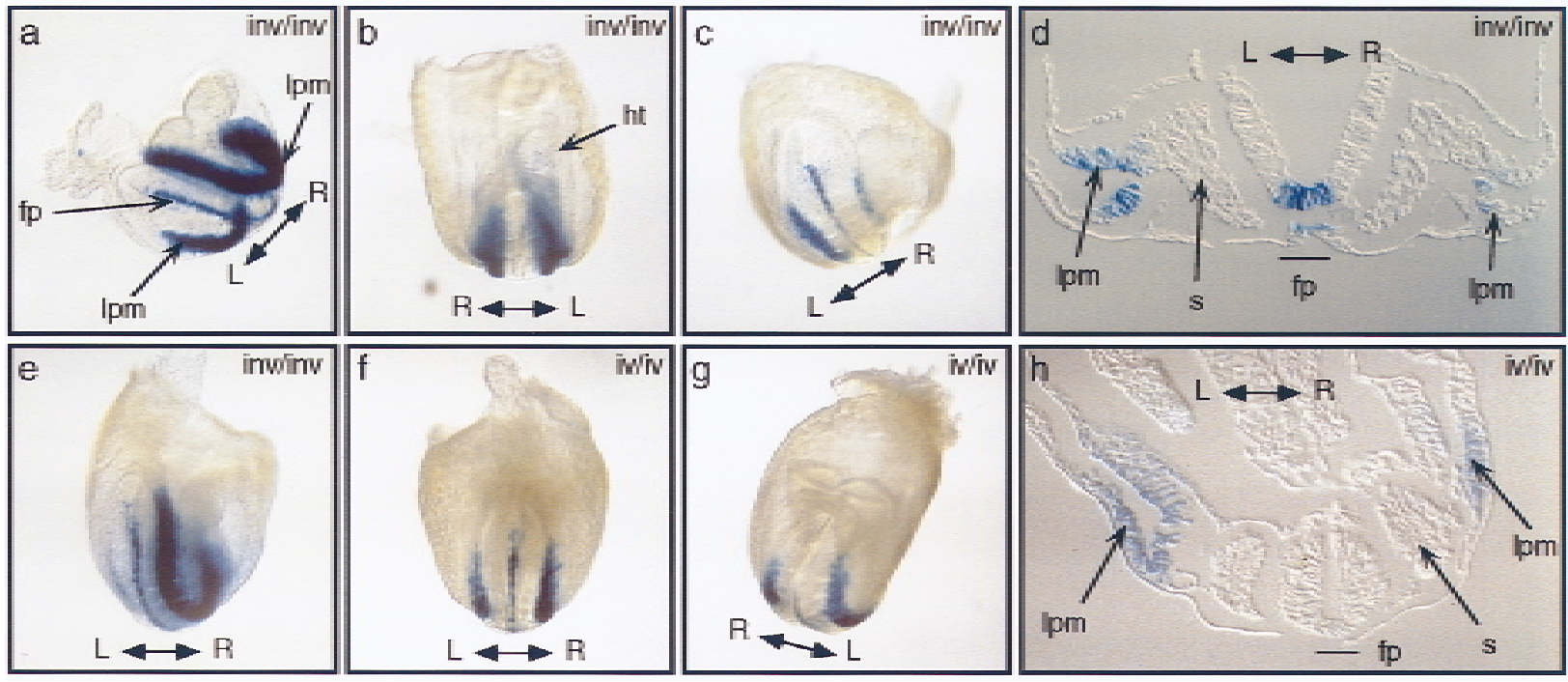

Figure 4. Perturbed C2 transgene expression in inv and iv mutant backgrounds. (a) Bilateral C2 expression in a presumed inv/inv embryo at $8.5 \mathrm{dpc}$. Notably staining is stronger on the right $(R)$ vs. left $(L)$ side of the embryo and expression in the floorplate is broader. (b) Anterior view of presumed inv/inv embryo. In addition to bilateral staining in the LPM, the heart tube (ht) is looping to the left rather than the right side, highlighting the reversal of situs. (c) Posterior view of a presumed inv/inv embryo showing increased lacZ expression on the left side. (d) Section through C2 inv/inv embryo. Staining is visible in the LPM on both sides of the axis. lacZ is expressed equally on both sides of the floorplate. (e) Posterior view of presumed inv/inv embryo in which lac $Z$ expression is confined to the LPM on the right side of the axis. $(f)$ Posterior view of a presumed iv/iv C2 transgenic embryo showing lac $Z$ expression is detectable in the right and left LPM. ( $g$ ) Anterior view of a presumed iv/iv C2 transgenic embryo. Expression is bilateral and truncated on the right as compared to the left side. (h) Section through a C2 iv/iv embryo showing LacZ staining in both the right and left lateral plate. 


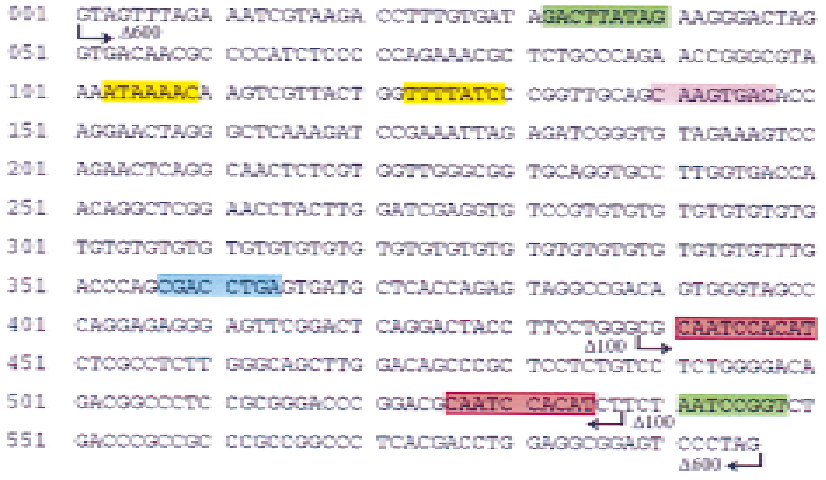

Figure 5. Nucleotide sequence of the minimal asymmetric enhancer element. The positions of putative transcription factor binding sites are indicated by the colored boxes. (Green) GATA; (yellow) HoxD; (pink) Mef1, MyoD, or Myf3; (blue) RXR $\alpha$. (red) A conserved 10-bp motif also present in the lefty-2 minimal asymmetric enhancer (Saijoh et al. 1999). Seven Sp1 and two NF- $\kappa$ B sites and a 65-bp CA repeat (between bases 284 and 350) are also present in this region. The arrows indicate the exact positions of the $\Delta 100$ and $\Delta 600$ deletions generated by homologous recombination. within the endogenous nodal locus via homologous recombination in ES cells. We engineered a large deletion $(\Delta 600)$ to eliminate the entire 596-bp subregion and also a second smaller 100 -bp deletion $(\Delta 100)$ that selectively removes the two potential 10-bp transcription factor binding sites (Fig. 5). The targeting vectors were designed to insert a LoxP-flanked hygromycin resistance cassette in place of the corresponding genomic region that, following drug selection, was removed by transient expression of Cre recombinase. We used ES cells heterozygous for the IRES-lacZ reporter allele (Collignon et al. 1996) to facilitate analysis of nodal expression patterns. Figure 6 shows the targeting strategy and Southern blot analysis used to identify recombinant ES cell clones harboring deletions in the context of the IRES-lac $Z$ allele.

We initially characterized LacZ staining patterns in chimeric embryos. As ES cells show a marked developmental bias when injected into recipient blastocysts (Beddington and Robertson 1989), this strategy only allowed us to examine potentially altered nodal expression patterns in derivatives of the epiblast. At $\sim 6$ days of development (the earliest stage recovered), chimeric em-
Figure 6. Targeted deletion of the minimal asymmetric enhancer. (a) The targeting vectors contained a lox-flanked PGKhygromycin cassette in place of intron 1 sequences (green circle). Homologous recombination in ES cells heterozygous for the nodal.lacZ allele (Collignon et al. 1996), specifically at the nodal.lacZ locus results in the appearance of a 12-kb SpeI (Sp) fragment. Following Cre-mediated recombination, clones in which the hygromycin cassette has been correctly excised were identified by digestion with HindIII $(\mathrm{H})$ and probing with SS1/1 (Conlon et al. 1991). In the case of the $\Delta 600$ deletion construct, Cre-mediated excision converts the $6-\mathrm{kb}$ fragment to $3.5 \mathrm{~kb}$. In the case of the $\Delta 100$ deletion construct, a $4.0-\mathrm{kb}$ HindIII fragment is generated. (b) Southern blot analysis of SpeI-digested DNA from drug resistant clones. (c) Southern blots of HindIII-digested DNA isolated following transient transfection with Cre-recombinase. The 6-kb band corresponds to the correctly targeted nodal.lac $Z$ allele $(\mathrm{T})$ whereas the wild-type allele gives rise to a $4-\mathrm{kb}$ fragment. In the case of the $\Delta 600$ construct, correct excision of the hygro cassette yields a $3.5-\mathrm{kb}$ fragment. In the case of the $\Delta 100$ construct, correct excision results in a $4.0-\mathrm{kb}$ fragment that comigrates with the wild-type product.

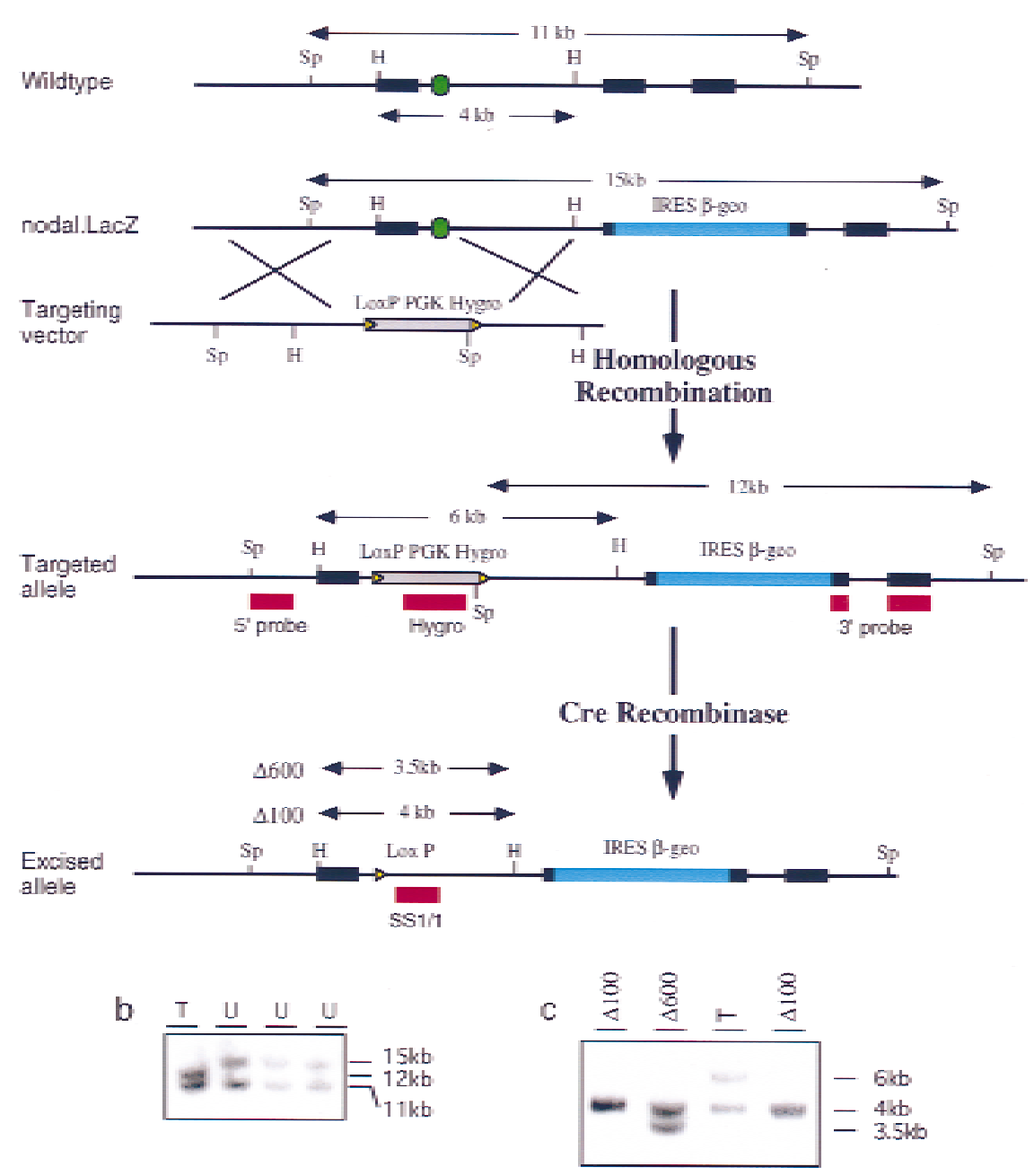


bryos carrying the $\Delta 600$ allele showed most intense expression in a ring of epiblast cells adjacent to the embryonic/extraembryonic boundary, and LacZ staining is largely absent from the prospective anterior of the embryo (Fig. 7a). A few hours later, this expression domain has resolved to the posterior side where the streak is developing (Fig. 7a). By four- to five-somite stages, expression is exclusively detected in the node (Fig. 7b). The $\Delta 100$ allele gave similar results in this transient analysis (Fig. 7c,d).

Based on these observations, ES cell clones carrying the $\Delta 100$ allele were used to generate germ-line chimeras, and embryos carrying this deletion were analyzed in detail. The onset of $\beta$-gal staining differs markedly from that normally observed for the endogenous locus, as the $\Delta 100.1 a c Z$ allele fails to show any appreciable expression at $5.5 \mathrm{dpc}$ (data not shown). At $\sim 6.0 \mathrm{dpc}$, expression is detectable in a circumferential ring of proximal epiblast cells (Fig. 8a). As for wild-type nodal, expression becomes restricted proximally and then posteriorly within the epiblast immediately prior to streak formation (Fig. $8 \mathrm{~b}, \mathrm{~d})$. Notably, lac $Z$ activity is absent from the visceral endoderm (Fig. 8c). Concomitant with the onset of gastrulation, expression is confined to the posterior epiblast and persists in nascent mesoderm emerging from the proximal streak (Fig. 8e). We failed to detect lac $Z$ expression at three- to four-somite stages in LPM on either side

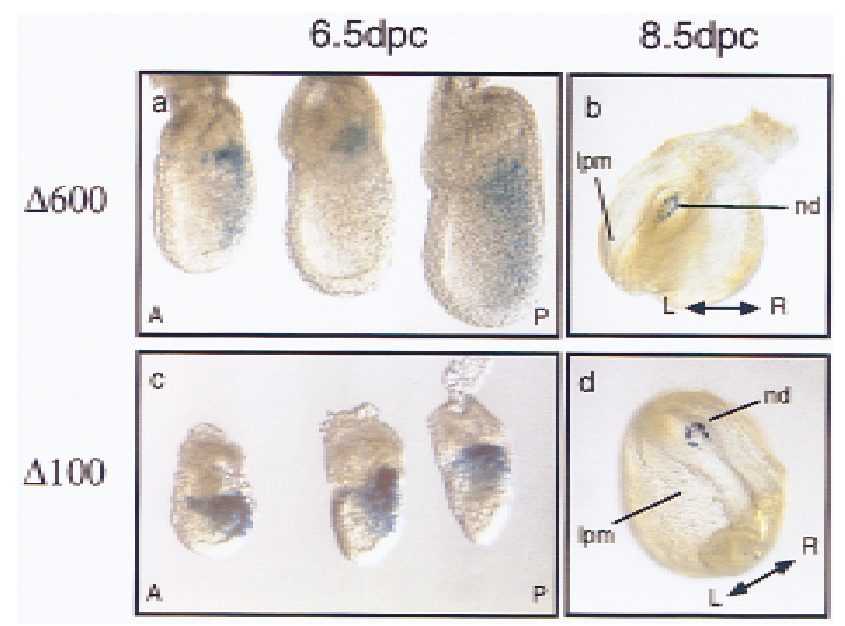

Figure 7. Transient analysis of nodal expression in chimeric embryos. (a) Chimeric embryos recovered at $6.5 \mathrm{dpc}$ following injection of ES cells carrying the $\Delta 600$ deletion. nodal.lacZ expression is observed primarily in cells occupying the most proximal posterior regions of the embryo and absent from the distal and prospective anterior epiblast. (b) In chimeric embryos recovered at $8.5 \mathrm{dpc}$ ( $3-5$ somites), nodal.lac $Z$ expression is confined to cells in the periphery of the mature node. No lacZpositive cells are detectable in left lateral plate mesoderm. (c) Chimeric embryos recovered at $6.5 \mathrm{dpc}$ following injection of ES cells carrying the $\Delta 100$ deletion. nodal.lacZ expression is confined to the proximal posterior region of the epiblast marking the site of the primitive streak formation. (d) At 8.5 dpc (3-5 somites) strong nodal.lacZ expression can be seen in the ventral lateral cells of the node, but no staining is visible in cells of the lateral plate. of the axis (Fig. 8g). Moreover, asymmetric expression within the notochordal plate is also eliminated (Fig. 8j). Interestingly, we observed very weak expression of $\beta$-gal activity in the left LPM in seven- to eight-somite stage embryos (Fig. 8h). This highly transient expression domain is no longer detectable by the 10-somite stage (Fig. 8i). Overall the early pre- and postgastrulation staining patterns associated with the $\Delta 100.1 a c Z$ allele are quite similar to those seen above with the $\mathrm{C} 4$ transgene. The results above suggest that distinct regulatory elements controlling nodal transcription in the proximal epiblast likely map outside of the $\Delta 100$-bp deletion.

\section{Discussion}

Highly dynamic and transient nodal expression patterns control functional activities essential for anterior patterning, primitive streak formation, and L-R axis determination. Our results demonstrate that node-specific and asymmetric nodal gene expression is governed by two distinct cis-acting regulatory elements. Thus, a $5^{\prime}$ flanking region mapping between -7.5 and $-10.2 \mathrm{~kb}$ upstream of the nodal promoter was found to direct nodespecific expression, whereas a 596-bp intronic enhancer confers early expression in the epiblast and the visceral endoderm and also acts at later stages to direct asymmetric expression in left LPM. The essential contribution made by a 100 -bp genomic subregion in regulating early expression in the visceral endoderm and the epiblast, as well as asymmetric expression at later stages in the lateral plate, has been established via targeted deletion.

Classical tissue grafting experiments clearly demonstrate that the signals responsible for organizing the posterior body plan originate in the node, a distinct embryonic structure originally identified in amphibian embryos by its ability to induce an ectopic second axis. Similarly, the mouse node isolated from late-streak stage embryos can induce the formation of a second axis containing host-derived neural and somitic tissues (Beddington 1994). However, the molecular pathways responsible for formation and maintenance of the node remain ill defined (for review, see Beddington and Robertson 1999). The mouse node is comprised of two distinct cell layers. The proximal layer is thought to give rise to the floor plate of the neural tube, whereas the ventral surface, the notochordal plate, gives rise to the notochord and perhaps the definitive endoderm of the gut (Sulik et al. 1994; Tam and Behringer 1997). nodal expression is strictly confined to the lateral edges of the notochordal plate during late gastrulation stages.

The present experiments identify a region upstream of the nodal promoter that specifically directs expression in the developing node. As for endogenous nodal, transgene expression is initially observed at the base of the primitive streak in a population of presumed node precursors and, following morphological appearance of the overt node, becomes highly restricted to the lateral edges of the ventral layer of cells constituting the notochordal plate (Collignon et al. 1996). A number of potential tran- 


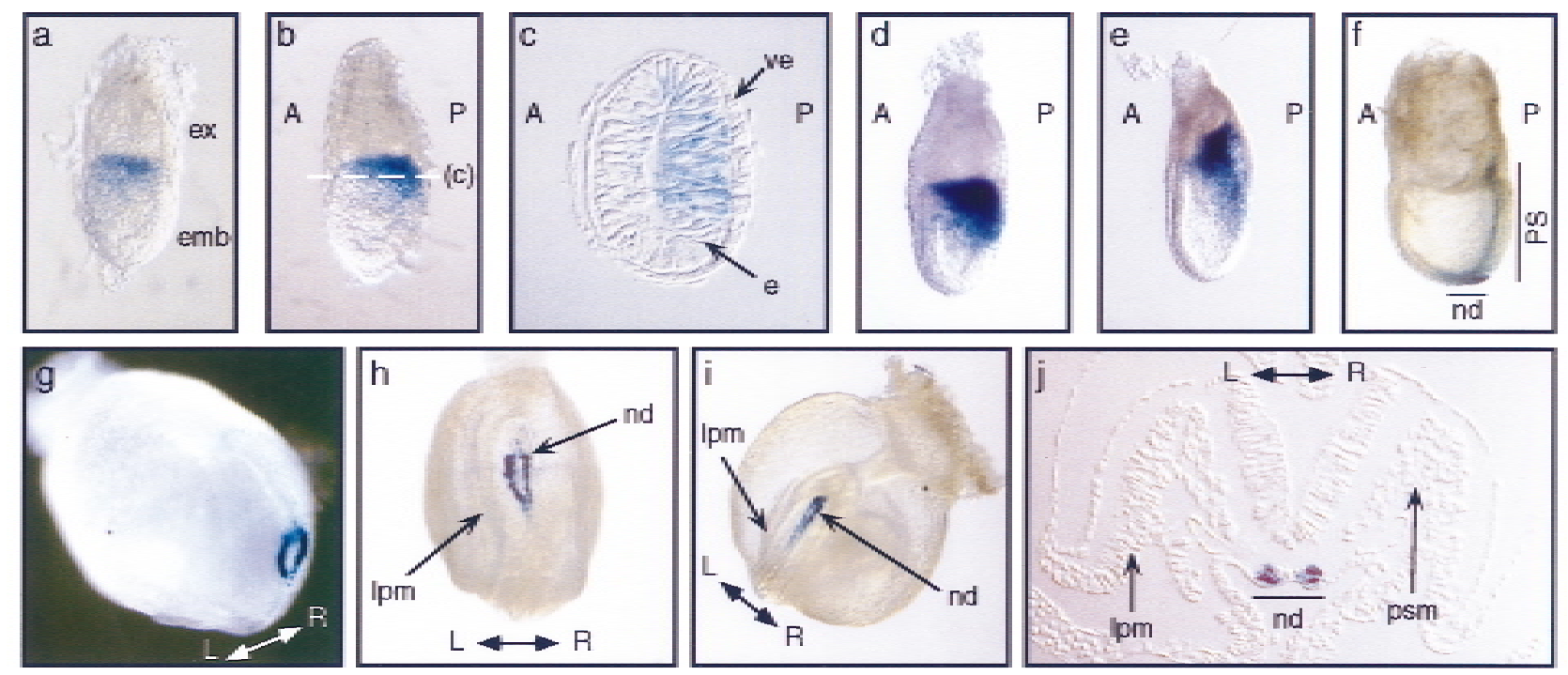

Figure 8. Node-specific nodal expression domains in embryos carrying a germ-line deletion of the 100-bp minimal asymmetric enhancer. (a) $\Delta 100$ nodal.lacZ expression is initially detected at $5.5 \mathrm{dpc}$ and is strictly confined to proximal epiblast cells. $(b, c)$ At pregastrulation stages $(6.0 \mathrm{dpc}) \Delta 100$ nodal.lacZ expression has resolved to the proximal epiblast population on the prospective posterior side of the embryo. Expression is noticeably absent from the visceral endoderm. ( $d-f$ ) At later stages subsequent to formation and elongation of the primitive streak, $\Delta 100$ nodal.lacZ expression closely resembles that seen from the endogenous locus (see Fig. 2). $(\mathrm{g})$ At the four-somite stage $\Delta 100$ nodal.lac $Z$ expression is confined to the node. The modified allele is not active in the lateral plate mesoderm. (h) At the eight-somite stage weak LacZ staining is detected in the left lateral plate mesoderm along the length of the axis. (i) By the ten-somite stage $\Delta 100$ nodal.lac $Z$ expression is strictly confined to the developing tail bud and posterior notochord. (j) Frontal section through the posterior region of a five-somite stage $\Delta 100$ nodal.lacZ/+ embryo, showing symmetric expression at the lateral edges of the notochordal plate. The modified $\Delta 100$ nodal allele is not expressed in LPM. (psm) Presomitic mesoderm.

scription factor binding motifs including HNF3-like and LEF-1/TCF sites appear scattered across the 2.7-kb C4d genomic fragment (J. Brennan, D.P. Norris, and E.J. Robertson, unpubl.). The winged helix factor HNF3 $\beta$ is strongly expressed in the anterior streak and then in the node, notochord, and floor plate (Ang et al. 1993; Monaghan et al. 1993; Sasaki and Hogan 1993), where it is required for the formation of these midline organizing structures (Ang and Rossant 1994; Weinstein et al. 1994). Wnt8 and Wnt11 are abundantly expressed in the node (Bouillet et al. 1996; Kispert et al. 1996) and are also potential candidates for regulating nodal transcription. Moreover LEF-1/TCF-binding sites in the Xnr-3 promoter have been implicated in regulating expression, suggesting $X n r-3$ is a wnt signaling target (McKendry et al. 1997). The possible contributions made by HNF3 $\beta$ and LEF-1/TCF transcription factors in controlling this node-specific expression domain are currently being investigated.

A strong argument has been made in chick that nodal asymmetry in Hensen's node initiates downstream signaling events essential for asymmetric nodal expression in the lateral plate (Levin et al. 1995, 1997). In mouse, mutations disrupting node morphogenesis also lead to defects in the establishment of L-R asymmetry (Dufort et al. 1998; Nonaka et al. 1998; King et al. 1999). The present data strongly suggest that the transient but pronounced asymmetry of nodal expression in the mouse node requires cooperative actions of two distinct enhancer regions. Thus, we observe that the node enhancer alone drives equivalent expression on both sides of the node, and targeted deletion of the asymmetric enhancer results in a similar pattern of node-specific expression. The upstream enhancer region is thus sufficient for activating expression in the notochordal plate, but these sequences alone fail to confer asymmetry in the node. We suggest the additional regulatory sequences responsible for node asymmetry may be contributed by the intron 1 enhancer. It will be of considerable interest to learn whether nodal expression in the node is a prerequisite for establishing asymmetric nodal and lefty-2 expression domains in the lateral plate, and whether asymmetric nodal signals are causally involved in inducing asymmetric lefty-1 expression in the floor plate. In normal embryos, nodal and lefty-2 transcripts are broadly expressed along most of the left side of the axis. Asymmetric expression is highly transient, and both transcripts are largely undetectable following the onset of embryonic turning. Assessment of the minimal asymmetric nodal and lefty-2 enhancers identified in transgenic experiments (Saijoh et al. 1999; Adachi et al. 1999; Fig. 3), together with the analysis of the 100-bp deletion allele, strongly implicate the highly conserved 10-bp motif (CAATCCAACAT) as a key regulatory element responsible for controlling asymmetric gene expression. Identification of transcription factor(s) binding to this minimal enhancer element promises to provide important insights into upstream components of the L-R pathway in mammals.

Cell-specific nuclear factors that potentiate left-sided 
expression or repress transcription on the right side of the embryo may cooperatively generate nodal and lefty asymmetry. Recent experiments suggest that both regulatory mechanisms govern asymmetric nodal expression in chick and Xenopus. Repression of shh transcription on the right side of the node in chick embryos, mediated by the activin signaling pathway, leads to selective nodal expression on the left side of Hensen's node and in the lateral plate (Levin et al. 1995, 1997). Moreover, expression of shh on the right side of the body axis causes ectopic nodal expression and situs defects (Levin et al. 1995). Misexpression of Xshh or Xbhh also induces ectopic $X n r-1$ on the right hand side of Xenopus embryos (Sampath et al. 1997). In contrast, in mouse the absence of Gli binding sites in both the nodal and lefty-2 asymmetric enhancers (Fig. 5; Saijoh et al. 1999), together with the observation that shh mutants establish normal situs (Chiang et al. 1996), implies that Shh signaling is not involved in the establishment of molecular asymmetry. In Xenopus, LPM isolated from either side of the body axis expresses $X n r-1$ when cultured in isolation (Lohr et al. 1997) suggesting that negative regulation normally prevents right-sided Xnr-1 expression. In mouse, lefty-1 asymmetric expression in the floor plate also appears to be mediated in part by a right-sided repressor contained within the lefty-1 locus (Saijoh et al. 1999). To date we have failed to identify similar repressor elements mapping to the nodal locus. On the other hand, C2 transgenes show asymmetric expression in the floor plate, implicating cis-acting regulatory sequences possibly shared with the lefty-1 and lefty-2 genes (Meno et al. 1997). The activity of the C2 asymmetric enhancer is disturbed in both the inv and iv mutant backgrounds. Notably, a high proportion of mutant embryos show bilateral expression of the C2 transgene, whereas, particularly in the case of the inv mutation, expression of endogenous nodal transcripts is predominantly reversed (Table 1; Collignon et al. 1996; Lowe et al. 1996). This discrepancy is perplexing considering C2 transgene expression is invariantly left-sided in wild-type embryos. Perhaps a repressor selectively acts to eliminate rightsided expression in wild-type embryos, but limiting amounts of transcriptional regulators may fail to bind all possible target sites on multicopy transgenes in the inv and iv mutant backgrounds.

Antivin, a lefty homolog recently described in zebrafish, has been shown to antagonize activin signaling, likely by binding to the activin type II receptor (Thisse and Thisse 1999|. Thus, coordinately regulated expression of nodal and lefty-2, a putative receptor antagonist, potentially modulates nodal signaling in the lateral plate. Mutation of ActRIIB leads to right isomerisms in mice (Oh and Li 1997), and in Xenopus overexpression of dominant-negative forms of this receptor block expression of the nodal target pitx2 (Ryan et al. 1998). Competitive binding of Lefty- 2 to activin type II receptors may therefore attenuate nodal signaling on the left side of the axis. On the other hand, expression of mouse Lefty proteins leads to ectopic nodal expression in chick (Yoshioka et al. 1998), implicating lefty as a positive regulator of nodal activity. Much additional work is needed to decipher the unique and shared roles of nodal and lefty signals during establishment of the mammalian L-R body axis.

Initially, widespread and uniform nodal expression in the early epiblast is gradually restricted to the prospective posterior side of the pregastrulation stage embryo (Varlet et al. 1997). Down-regulation first in the distal tip cells and shortly thereafter in the prospective anterior epiblast likely occurs in response to signals from both the overlying AVE as it rotates from the distal tip to the anterior side of the embryo, as well the proximal extraembryonic ectoderm (for review, see Beddington and Robertson 1999). Our results demonstrate epiblast expression is influenced by two distinct regions of the locus. Thus, a genomic region upstream of the locus $(\mathrm{C} 4$; -5 to $-12 \mathrm{~kb}$ ) confers expression in the proximal posterior region of the epiblast (Fig. 2), whereas the intronic enhancer directs the onset of widespread epiblast expression at $5.5 \mathrm{dpc}$ (Fig. 3). Interestingly, expression from the modified $\Delta 100$ allele closely resembles that described for $\mathrm{T}$ transcripts (Thomas and Beddington 1996). Thus, expression is first seen in a circumferential pattern in cells throughout the proximal rim of the epiblast and rapidly resolves to the prospective posterior region to mark the position of the streak (Fig. 8). In Smad2 mutant embryos, both $T$ and nodal are uniformly expressed throughout the epiblast (Waldrip et al. 1998) suggestive of coordinately regulated transcription in the proximal epiblast. The factors responsible for highly specific gene expression patterns during the complex process of mesoderm induction have yet to be elucidated.

nodal activities in the primitive endoderm are essential for the formation of the AVE and patterning of the rostral CNS (Varlet et al. 1997). Thus, Smad2 mutant embryos lacking nodal expression in the visceral endoderm fail to activate AVE-specific markers including cer1, lim-1, and hesx-1 and consequently fail to establish A-P polarity in the underlying epiblast (Waldrip et al. 1998). Surprisingly, the minimal asymmetric enhancer also controls nodal expression in the visceral endoderm. The minimal 596-bp C2g transgene is strongly expressed in the endoderm, and targeted deletion of a 100-bp fragment abolishes expression in this tissue (Fig. 8). Thus, this discrete genomic subregion not only controls asymmetric expression but also, remarkably, directs early nodal expression domains in the epiblast and primitive endoderm. Thus, the same signaling cues that act to induce nodal activity during early development to pattern the A-P axis may also govern asymmetric nodal expression at later stages to establish the L-R body axis.

\section{Materials and methods}

DNase I analysis

Chromatin was produced and DNaseI digestion was carried out according to the methods of Reik et al. (1991). DNA (10 mg) from each DNase I digestion was subsequently digested with EcoRI or SpeI, fractionated through a $0.8 \%$ agarose gel, then 
transferred. Southern blots were probed with the SS1/ 1 (Conlon et al. 1991) and the Nodal 5' probe (Collignon et al. 1996). Restriction sites and probes are indicated in Figure 1, with the exception of the $5^{\prime}$ SpeI site $\sim 0.5 \mathrm{~kb}$ upstream of the C4 fragment.

\section{Cloning and production of reporter constructs}

Genomic subclones spanning the entire nodal locus were isolated from 129Sv libraries. Fragments downstream from the first exon were recovered from the cosmid clone described previously (Collignon et al. 1996). Lambda clones containing upstream sequence extending $\sim 12 \mathrm{~kb} 5^{\prime}$ from the end of exon 1 were obtained from a Stratagene mouse genomic library (no. 946313) using the nodal 5' genomic probe (Collignon et al. 1996). For constructs C1, C2, and C4, the genomic subclones were cloned into the hsp68lacZpA reporter construct (Sasaki and Hogan 1996). However, for C2, the lacZ locus was placed immediately downstream of the ATG of nodal. The transcriptional start site of nodal in the cDNA clone was mutated from ATGAGT to an NcoI site (ATGCAT) to allow ligation to the NcoI site at the start of the lacZ.poly(A) cassette recovered from a Wnt1 minimal promoter.lacZ construct (Echelard et al. 1994), with no loss of sequence.

\section{Production of transgenic embryos}

DNA for injection was purified using Qiagen P100 columns. Following digestion with appropriate enzymes, fragments were gel fractionated and electroeluted into TAE buffer $(0.04 \mathrm{M}$ Trisacetate, 0.001 M EDTA at $\mathrm{pH}$ 8), concentrated using Wizard Prep kit (Promega), and recovered in injection buffer $(10 \mathrm{~mm}$ Tris at $\mathrm{pH} 7.5,0.1 \mathrm{~mm}$ EDTA). Fertilized eggs from ICR mice (Taconic) were collected for pronuclear injection according to standard procedures (Hogan et al. 1994). Injected eggs were transferred to pseudopregnant $(\mathrm{C} 57 \mathrm{BL} 6 / \mathrm{J} \times \mathrm{CBA} / \mathrm{J}) \mathrm{F}_{1}$ females. For $\mathrm{F}_{0}$ analysis, foster mothers were sacrificed and embryos retrieved for further analysis. Live-born offspring were genotyped by Southern blot analysis of tail DNA using LacZ probes to identify transgenic animals.

\section{LacZ staining and histology}

Embryos were collected and LacZ stained according to standard protocols (Hogan et al. 1994). Noon on the day of finding vaginal plugs was designated as 0.5 day of development. For sectioning, embryos were washed in PBS and postfixed overnight in $4 \%$ paraformaldehyde. Embryos were washed in PBS, dehydrated through an ethanol series, cleared in xylenes, and embedded in paraffin wax. Sections $(8 \mu \mathrm{m})$ were taken, dewaxed in xylenes, and mounted under coverslips with Cytoseal (Stephens Scientific).

\section{Generation and analysis of targeted mutations}

To produce the $\Delta 600$ deletion construct, a PCR fragment flank-

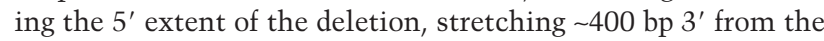
NotI site in exon 1 (primers: 5'-GGGGTACCGTCGACGCGGCCGCTTTGCCTCTGTGGA; 3'-GCGGATCCATGCATCTCGAGTCTAGATGGGCAAACTGAGACTCGCAGG), was cloned into pBSII (Stratagene). A LoxP-flanked PGKHygro cassette engineered such that Cre-mediated excision results in loss of both the PGK promoter and hygromycin-resistance gene was ligated $3^{\prime}$ to the $\Delta 600$ PCR fragment. The $3^{\prime}$ end of the $\Delta 600$ deletion is a PstI site $1 \mathrm{~kb} 3^{\prime}$ to the NotI site in exon 1. 3' Homology was therefore provided by the $4-\mathrm{kb}$ PstI-BamHI fragment, stretching from this PstI site to a BamHI site within exon
2. 5' Homology was provided by a 6-kb NotI-SalI genomic fragment stretching $5^{\prime}$ from the NotI site within exon 1 to the upstream SalI site shown in Figure 1. To produce the $\Delta 100$ deletion, PCR fragments abutting both sides of the deletion were produced; an 800-bp $\Delta 1005^{\prime}$ PCR fragment stretches from the $5^{\prime}$ extent of the deletion to the NotI site in exon 1 , whereas an $80-$ bp $\Delta 1003^{\prime}$ PCR fragment stretches from the $3^{\prime}$ extent of the deletion to the PstI site used in the production of $\Delta 600 . \Delta 100$ 5' fragment primers: GGGGTACCGTCGACGCGGCCGCTTTGCCTCTGTGGA; TCAGAATTCAGATCTCCCAGGAAGGTAGTCCTGAG. $\triangle 100$ 3'fragment primers: TCAGAATTCTCGAGACTAGTTCTAATCCGGTCTGACCCGC; TCAGGTACCGGATCCATGCATGCTGCAGGCAGGGGACTAGG. The $5^{\prime}$ and $3^{\prime}$ fragments were cloned either side of the LoxPflanked PGKHygro and sequence confirmed. The remaining regions of $3^{\prime}$ and $5^{\prime}$ homology were provided as for the $\Delta 600$ vector. The vectors were linearized with SalI and electroporated into nodal.1acZ/+ ES cells (Collignon et al. 1996), using standard procedures (Ramirez-Solis et al. 1993). Hygromycin-resistant colonies were picked into 96-well plates and screened by Southern blot analysis (Ramirez-Solis et al. 1993). DNA was digested with SpeI and separated on $0.6 \%$ agarose gels, blotted onto Hybond N membrane (Amersham), and probed using the 3' cDNA probe. Approximately 1 in 15 drug-resistant colonies had undergone the expected recombination event. Fidelity of the targeting event was confirmed with a nodal $5^{\prime}$ genomic probe (Collignon et al. 1996; Fig. 6) and hygromycin probe (Fig. 6). Correctly targeted ES cells were expanded and subjected to transient transfection with the MC1Cre expression vector. Cells grown for two days to allow recombination to occur were then low density plated. Colonies were isolated, DNA digested with HindIII, and separated through $0.8 \%$ agarose gels. Southern blots were analyzed with the SS1/1 probe (Conlon et al. 1991; Fig. 6) and clones that had excised the selection cassette were isolated and expanded. The targeting and excision events were confirmed by Southern blot analysis using the nodal $5^{\prime}$ genomic probe and the 3' cDNA probe. Recombinant ES cells carrying the deletions at the nodal.lacZ allele were injected into ICR blastocysts to generate chimeric embryos using standard procedures (Bradley 1987). Embryos were harvested at 6.5 and 8.5 days of development and LacZ stained. ES cells carrying the $\Delta 100$ deletion were injected into C57BL/6J blastocysts to generate live born chimeras. Highly chimeric males were mated to MF1 females and agouti offspring genotyped by Southern blot analysis using the $3^{\prime}$ cDNA probe. Chimeric males transmitting the correctly targeted $\Delta 100$ allele and their offspring were used to produce embryos for LacZ staining and histological analysis.

\section{Acknowledgments}

We are grateful to Dr. Hiroshi Hamada and his colleagues for exchanging data before publication. We thank Liz Bikoff for helpful suggestions throughout the course of this work and especially during preparation of the manuscript, Jane Brennan and Mark Solloway for critical review of the manuscript, David Rowitch for advice on transgenic techniques, Patti Lewko and Joe Rocca for careful animal maintenance, and Debbie Pelusi for help with genotyping. D.P.N. is a fellow of the Jane Coffin Childs Memorial Fund for Medical Research. This investigation has been aided by a grant from the Jane Coffin Childs Memorial Fund for Medical Research. This work was supported by a grant from the National Institutes of Health.

The publication costs of this article were defrayed in part by payment of page charges. This article must therefore be hereby marked 'advertisement' in accordance with 18 USC section 1734 solely to indicate this fact. 


\section{References}

Adachi, H., Y. Saijoh, K. Mochida, K. Oishi, and H. Hamada. 1999. Left-right asymmetric expression of nodal is controlled by a left side-specific enhancer. Genes \& Dev. (this issue).

Ang, S.-L. and J. Rossant. 1994. HNF-3 $\beta$ is essential for node and notochord formation in mouse development. Cell 78: 561574.

Ang, S.-L., A. Weirda, D. Wong, K.A. Stevens, S. Cascko, J. Rossant, and K.S. Zaret. 1993. The formation and maintenance of the definitive endoderm lineage in the mouse: Involvement of the HNF3/fork head proteins. Development 119: 1301-1315.

Beddington, R.S.P. 1994. Induction of a second neural axis by the mouse node. Development 120: 613-620.

Beddington, R.S.P. and E.J. Robertson. 1989. An assessment of the developmental potential of embryonic stem cells in the midgestation embyro. Development 105: 733-737.

- 1998. Anterior patterning in the mouse. Trends Genet. 14: $277-284$.

-1999. Axis development and early asymmetry in mammals. Cell 96: 195-209.

Bouillet, P., M. Oulad-Abdelghani, S.J. Ward, S. Bronner, P. Chambon, and P. Dolle. 1996. A new mouse member of the Wnt gene family, mWnt-8, is expressed during early embryogenesis and is ectopically induced by retinoic acid. Mech. Dev. 58: 141-152.

Bradley, A. 1987. Production and analysis of chimeric mice. In Teratocarcinomas and embryonic stem cells: A practical approach (ed. E.J. Robertson), pp. 131-151. IRL Press, Oxford, UK

Chiang, C., Y. Litingtung, E. Lee, J.L. Young, H. Westphal, and P. Beachy. 1996. Cyclopia and defective axial patterning in mice lacking Sonic Hedgehog gene function. Nature 383: 407-413.

Collignon, J., I. Varlet, and E.J. Robertson. 1996. Relationship between asymmetric nodal expression and the direction of embryonic turning. Nature 381: 155-158.

Conlon, F.L., K.S. Barth, and E.J. Robertson. 1991. A novel retrovirally-induced embryonic lethal mutation in the mouse; assessment of the developmental fate of ES cells homozygous for the 413.d proviral integration. Development 111: 969-981.

Conlon, F.L., K.M. Lyons, N. Takaesu, K.S. Barth, A. Kispert, B. Herrmann, and E.J. Robertson. 1994. A primary requirement for nodal in the formation and maintenance of the primitive streak in the mouse. Development 120: 1919-1928.

Dufort, D., L. Schwartz, K. Harpal, and J. Rossant. 1998. The transcription factor HNF3 $\beta$ is required in the visceral endoderm for normal primitive streak morphogensis. Development 125: 3015-3025.

Echelard, Y., G. Vassileva, and A. P. McMahon. 1994. Cis-acting regulatory sequences governing Wnt-1 expression in the developing mouse CNS. Development 120: 2213-2224.

Epstein, D.J., A.P. McMahon, and A. Joyner. 1999. Regionalization of Sonic hedgehog transcription along the anteroposterior axis of the mouse central nervous system is regulated by Hnf3-dependent and -independent mechanisms. Development 126: 281-292.

Feldman, B., M.A. Gates, E.S. Egan, S.T. Dougan, G. Rennebeck, H.I. Sirotkin, A.F. Schier, and W.S. Talbot. 1998. Zebrafish organiser development and germ layer formation require nodal-related signals. Nature 395: 181-184.

Gu, Z., M. Nomura, B.B. Simpson, H. Lei, A. Feijen, J. van den Eijnden-van Raaij, P.K. Donahoe, and E. Li. 1998. The type I activin receptor ActRIB is required for egg cylinder organization and gastrulation in the mouse. Genes \& Dev. 15: 844857.

Hansen, C.S., C.D. Marion, K. Steele, S. George, and W.C. Smith. 1997. Direct neural induction and selective inhibition of mesoderm and epidermis inducers by Xnr3. Development 124: 483-492.

Harvey, R.P. 1998. Links in the left/right axial pathway. Cell 94: $273-276$.

Heinemeyer, T., E. Wingender, I. Reuter, H. Hermjakob, A.E. Kel, O.V. Kel, E.V. Ignatieva, E.A. Ananko, O.A. Podkolodnaya, F.A. Kolpakov, N.L. Podkolodny, and N.A. Kolchanov. 1998. Databases on transcriptional regulation: TRANSFAC, TRRD, and COMPEL. Nucleic Acids Res. 26: 362-367.

Hogan, B., R. Beddington, F. Costantini, and E. Lacy. 1994. Manipulating the mouse embryo: A laboratory manual. Cold Spring Harbor Laboratory, Cold Spring Harbor, NY.

Hummel, K.P. and D.B. Chapman. 1959. Visceral inversion and associated anomalies in the mouse. J. Hered. 50: 9-23.

Isaac, A., M.G. Sargent, and J. Cooke. 1997. Control of vertebrate left-right asymmetry by a snail-related zinc finger gene. Science 275: 1301-1304

Jones, C.M., M.R. Kuehn, B.L.M. Hogan, J.C. Smith, and C.V.E. Wright. 1995. Nodal-related signals induce axial mesoderm and dorsalize mesoderm during gastrulation. Development 121: 3651-3662.

Joseph, E.M. and D.A. Melton. 1997. Xnr4: A Xenopus nodalrelated gene expressed in the Spemann organizer. Dev. Biol. 184: 367-372.

King, T., R.S.P. Beddington, and N.A. Brown. 1999. The role of the brachyury gene in heart development and left-right specificiation in the mouse. Mech. Dev. 79: 29-37.

Kispert, A., S. Vainio, L. Shen, D.H. Rowitch, and A.P. McMahon. 1996. Proteoglycans are required for maintenance of Wnt-11 expression in the ureter tips. Development 122: 3627-3637.

Levin, M., R.L. Johnson, C.D. Stern, M. Kuehn, and C. Tabin. 1995. A molecular pathway determining left-right asymmetry in chick embryogenesis. Cell 82: 803-814.

Levin, M., S. Pagan, D. Roberts, J. Cooke, M. Kuehn, and C. Tabin. 1997. Left/right signals and the independent regulation of different aspects of situs in the chick embryo. Dev. Biol. 189: 57-67.

Logan, M., S.M. Pagan-Westphal, D.M. Smith, L. Paganessi, and C.J. Tabin. 1998. The transcription factor Pitx2 mediates situs-specific morphogenesis in response to left-right asymmetric signals. Cell 94: 307-317.

Lohr, J.L., M.C. Danos, and H.J. Yost. 1997. Left-right asymmetry of a nodal-related gene is regulated by dorsoanterior midline structures during Xenopus development. Development 124: $1465-1472$.

Lowe, L.A., D.M. Supp, K. Sampath, T. Yokoyama, C.V.E. Wright, S.S. Potter, P. Overbeek, and M.R. Kuehn. 1996. Conserved left-right asymmetry of nodal expression and alterations in murine situs inversus. Nature 381: 158-161.

Lustig, K.D., K. Kroll, E. Sun, R. Ramos, H. Elmendorf, and M.W. Kirschner. 1996. A Xenopus nodal-related gene that acts in synergy with noggin to induce complete secondary axis and notochord formation. Development 122:32753282.

Massagué, J. 1996. TGF $\beta$ signaling: Receptors, transducers, and Mad proteins. Cell 85: 947-950.

- 1998. TGFß signal transduction. Annu. Rev. Biochem. 67: 753-791.

McKendry, R., S.C. Hsu, R.M. Harland, and R. Grosschedl. 1997. LEF-1/TCF proteins mediate wnt-inducible transcrip- 
tion from the Xenopus nodal-related 3 promoter. Dev. Biol. 192: 420-431.

Meno, C., Y. Saijoh, H. Fujii, M. Ikeda, T. Yokoyama, M. Yokoyama, Y. Toyoda, and H. Hamada. 1996. Left-right asymmetric expression of the TGF $\beta$-family member lefty in mouse embryos. Nature 381: 151-155.

Meno, C., Y. Ito, Y. Saijoh, Y. Matsuda, K. Tashiiro, S. Kuhara, and H. Hamada. 1997. Two closely related left-right asymmetrically expressed genes, lefty- 1 and lefty-2: Their distinct expression domains, chromosomal linkage and direct neuralizing activity in Xenopus embryos. Genes Cells 2: 513-524.

Mishina, Y., A. Suzuki, N. Ueno, and R.R. Behringer. 1995. Bmpr encodes a type I bone morphogenetic protein receptor that is essential for gastrulation during mouse embryogenesis. Genes \& Dev. 6: 432-438.

Mochizuki, T., Y. Saijoh, K. Tsuchiya, Y. Shirayoshi, S. Takai, C. Taya, H. Yonekawa, K. Yamada, H. Nihei, N. Nakatsuji, P.A. Overbeek, H. Hamada, and T. Yokoyama. 1998. Cloning of inv, a gene that controls left/right asymmetry and kidney development. Nature 395: 177-181.

Monaghan, A.P., K.H. Kaestner, E. Grau, and G. Schütz. 1993. Postimplantation expression patterns indicate a role for the mouse forkhead/HNF-3 $\alpha, \beta$ and $\gamma$ genes in determination of the definitive endoderm, chordamesoderm and neuroectoderm. Development 119: 567-578.

Morgan, D., L. Turnpenny, J. Goodship, W. Dai, K. Majumder, L. Matthews, A. Gardner, G. Schuster, L. Vien, W. Harrison, F.F.B. Elder, M. Pennmannsplitt, P. Overbeek, and T. Strachan. 1998. Inversin, a novel gene in the vertebrate left-right axis pathway, is partially deleted in the inv mouse. Nat. Genet. 20: 149-156.

Nonaka, S., Y. Tanaka, Y. Okada, S. Takeda, A. Harada, Y. Kanai, M. Kido, and N. Hirokawa. 1998. Randomization of leftright asymmetry due to loss of nodal cilia generating leftward flow of extraembryonic fluid in mice lacking KIF3B motor protein. Cell 95: 829-837.

Oh, S.P. and E. Li. 1997. The signaling pathway mediated by the type IIB activin receptor controls axial patterning and lateral asymmetry in the mouse. Genes \& Dev. 11: 1812-1826.

Piccolo, S., E. Agius, L. Leyns, S. Bhattacharyya, H. Grunz, T. Bouwmeester, and E.M. De Robertis. 1999. The head inducer Cerberus is a multifunctional antagonist of Nodal, BMP and Wnt signals. Nature 397: 707-710.

Piedra, M.E., J.M. Icardo, M. Albajar, J.C. Rodriguez-Rey, and M.A. Ros. 1998. Pitx2 participates in the late phase of the pathway controlling left-right asymmetry. Cell 94: 319-324.

Ramirez-Solis, R., A.C. Davis, and A. Bradley. 1993. Gene targeting in embryonic stem cells. Methods Enzymol. 225: 855-877.

Rebagliati, M.R., R. Toyama, P. Haffter, and I.B. Dawid. 1998a. cyclops encodes a nodal-related factor involved in midline signaling. Proc. Nat1. Acad. Sci. 95: 9932-9937.

Rebagliati, M.R., R. Toyama, C. Fricke, P. Haffter, and I.B. Dawid. 1998b. Zebrafish nodal-related genes are implicated in axial patterning and establishing left-right asymmetry. Dev. Biol. 199: 261-272.

Reik, A., G. Schütz, and A.F. Stewart. 1991. Glucocorticoids are required for establishment and maintenance of an alteration in chromatin structure: Induction leads to a reversible disruption of nucleosomes over an enhancer. EMBO J. 10: 2569-2576.

Ryan, A.K., B. Blumberg, C. Rodriguez-Esteban, S. YoneiTamura, K. Tamura, T. Tsukui, J. de la Pena, W. Sabbagh, J. Greenwald, S. Choe, D.P. Norris, E.J. Robertson, R.M. Evans, M.G. Rosenfeld, and J.-C. Izpsisua-Belmonte. 1998. Pitx2 determines left-right asymmetry of internal organs in vertebrates. Nature 394: 545-551.

Saijoh, Y., H. Adachi, K. Mochida, S. Ohishi, A. Hirao, and H.
Hamada. 1999. Distinct transcriptional regulatory mechanisms underlie left-right asymmetric expression of lefty-1 and lefty-2. Genes \& Dev. 13: 259-269.

Sampath, K., A.M.S. Cheng, A. Frisch, and C.V.E. Wright. 1997. Functional differences among Xenopus nodal-related genes in left-right axis determination. Development 124: 3293-3302.

Sampath, K., A.L. Rubinstein, A.M.S. Cheng, J.O. Liang, K. Fekany, L. Solnica-Krezel, V. Korzh, M.E. Halpern, and C.V.E. Wright. 1998. Induction of the zebrafish ventral brain and floorplate requires cyclops/nodal signaling. $\mathrm{Na}$ ture 395: 185-189.

Sasaki, H. and B.L.M. Hogan. 1993. Differential expression of multiple fork head related genes during gastrulation and axial pattern formation in the mouse embryo. Development 118: 47-59.

. 1996. Enhancer analysis of the mouse HNF-3 $\beta$ gene: Regulatory elements for node/notochord and floor plate are independent and consist of multiple sub-elements. Genes Cells 1: 59-72.

Smith, W.C., R. McKendry, S. Ribisi, Jr., and R.M. Harland. 1995. A nodal-related gene defines a physical and functional domain within the Spemann organizer. Cell 82: 37-46.

Sulik, K., D.B. Dehart, T. Inagaki, J.L. Vrablic, K. Gesteland, and G.C. Schoenwolf. 1994. Morphogenesis of the murine node and notochordal plate. Dev. Dyn. 201: 260-278.

Supp, D., D. Witte, S. Potter, and M. Brueckner. 1997. Mutation of an axonemal dynein affects left-right asymmetry in inversus viscerum mice. Nature 389: 963-966.

Tam, P.P. and R.R. Behringer. 1997. Mouse gastrulation: The formation of a mammalian body plan. Mech. Dev. 68: 3-25.

Thisse, C. and B. Thisse. 1999. Antivin, a novel and divergent member of the TGF $\beta$ superfamily, negatively regulates mesoderm induction. Development 126: 229-240.

Thomas, P. and R.S.P. Beddington. 1996. Anterior primitive endoderm may be responsible for patterning the anterior neural plate in the mouse embryo. Curr. Biol. 6: 1487-1496.

Varlet, I., J. Collignon, and E.J. Robertson. 1997. Nodal expression in the primitive endoderm is required for the specification of the anterior axis during mouse gastrulation. Development 122: 1033-1044.

Waldrip, W.R., E.K. Bikoff, P.A. Hoodless, J.L. Wrana, and E.J. Robertson. 1998. Smad2 signaling in extraembryonic tissues determines anterior-posterior polarity of the early mouse embryo. Cell 92: 797-808.

Weinstein, D.C., A. Ruiz i Altaba, W.S. Chen, P. Hoodless, V.R. Prezioso, T.M. Jessell, and J.E. Darnell, Jr. 1994. The wingedhelix transcription factor HNF-3 $\beta$ is required for notochord development in the mouse embryo. Cell 78: 575-588.

Whitman, M. 1998. Smads and early developmental signaling by the TGF $\beta$ superfamily. Genes \& Dev. 12: 2445-2462.

Wrana, J.L., L. Attisano, R. Wieser, F. Ventura, and J. Massagué. 1994. Mechanism of activation of the TGF-beta receptor. Nature 370: 341-347.

Yokoyama, T., N.G. Copeland, N.A. Jenkins, C.A. Montgomery, F.F. Elder, and P.A. Overbeek. 1993. Reversal of leftright asymmetry: A situs inversus mutation. Science 260: 679-682.

Yoshioka, H., C. Meno, K. Koshiba, M. Sugihara, H. Itoh, Y. Ishimura, T. Inoue, H. Ohuchi, E. Semina, J.C. Murray, H. Hamada, and S. Noji. 1998. Pitx2, a bicoid-type homeobox gene, is involved in a lefty-signaling pathway in determination of left-right asymmetry. Cell 94: 299-305.

Zhou, X., H. Sasaki, L. Lowe, B.L.M. Hogan, and M.R. Kuehn. 1993. Nodal is a novel TGF $\beta$-like gene expressed in the mouse node during gastrulation. Nature 361: 543-547. 


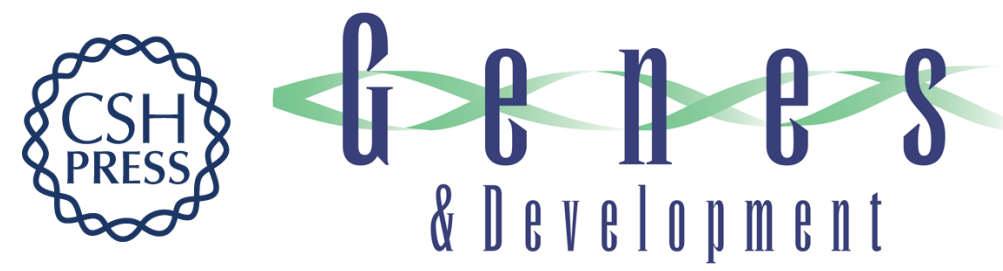

\section{Asymmetric and node-specific nodal expression patterns are controlled by two distinct cis-acting regulatory elements}

Dominic P. Norris and Elizabeth J. Robertson

Genes Dev. 1999, 13:

\section{License}

Email Alerting Receive free email alerts when new articles cite this article - sign up in the box at the top Service right corner of the article or click here.

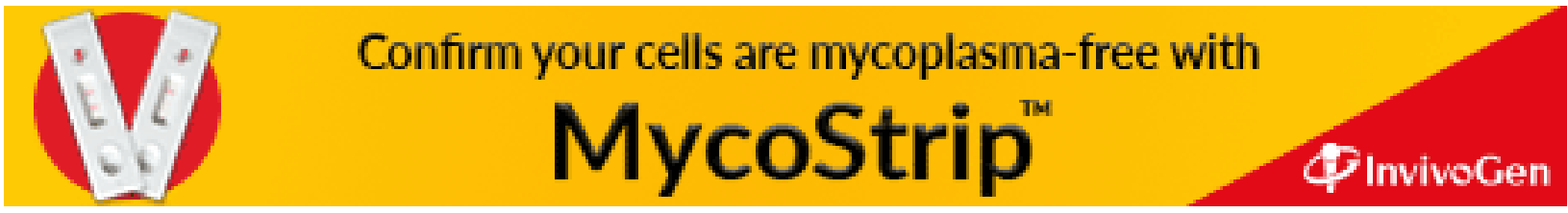

